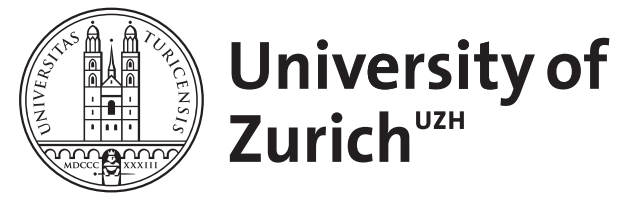

Die Einsamkeit im Liebesblick: Zur deutschen und persischen Liebeslyrik des 17. Jahrhunderts

\author{
Schnyder, Mireille
}

Posted at the Zurich Open Repository and Archive, University of Zurich ZORA URL: https://doi.org/10.5167/uzh-93922

Journal Article

Originally published at:

Schnyder, Mireille (1996). Die Einsamkeit im Liebesblick: Zur deutschen und persischen Liebeslyrik des 17. Jahrhunderts. Deutsche Vierteljahrsschrift für Literaturwissenschaft und Geistesgeschichte, 70:369393. 


\section{Sonderdruck aus: $\quad$ E20461F \\ DEUTSCHE \\ VIERTELJAHRS \\ SCHRIFT \\ FÜR \\ LITERATURWISSENSCHAFT \\ UND \\ GEISTESGESCHICHTE}

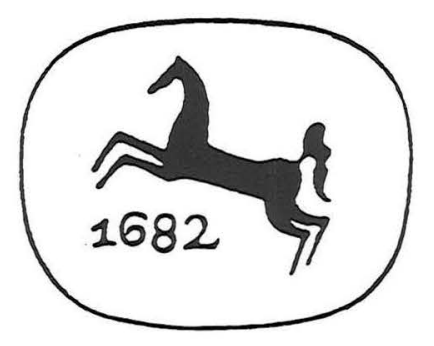

\begin{tabular}{lll}
\hline 70. JAHRGANG & 1996 & HEFT 3/SEPTEMBER \\
\hline
\end{tabular}

VERLAG J.B. METZLER

STUTTGART · WEIMAR 


\title{
Die Einsamkeit im Liebesblick Zur deutschen und persischen Liebeslyrik des 17. Jahrhunderts
}

\author{
Von Mireille Schnyder (Zürich)
}

\begin{abstract}
Das petrarkistische Liebeskonzept mit seinem Schlagwort ,dolendi voluptas' hat in der persischen Lyrik seine Entsprechung. Auf dem Hintergrund der Tradition der Liebespathologie spürt der folgende Aufsatz, im Blick auf das Auge, den verdichteten erotischen Spielereien in Ost und West nach, faßt sich dieser Liebesdiskurs im dunklen Auge doch zum prägnanten und geistvollen Bild.

The petrarchistic love conceit, with its key phrase, dolendi voluptas', has ist equivalent in Persian literature. Taking the tradition of the pathology of love as its background, this article traces poetic erotics in the East and West by focusing on the eye. In the darkness of the beloved's eye this discourse of love finds a concise and pregnant image.
\end{abstract}

Die Grausamkeit im Auge der Geliebten, beziehungsweise des Geliebten, wie sie die europäische petrarkistische Dichtung kennt, wie sie aber auch fester Topos der persischen Liebeslyrik ist, hat ihre grosse Geschichte, in deren Spiegel sich die zwei scheinbar so verschiedenen Welten plötzlich übereinanderschieben.

Der folgende Artikel will anhand einer Interpretation exemplarischer Beispiele der Bedeutung des Auges in der deutschen und persischen Liebesdichtung des 17.Jahrhunderts nachgehen. Dabei soll die Gegenüberstellung der zwei Literaturen den Blick schärfen für die je eigene Umsetzung ursprünglich gleicher Vorstellungen. Denn spricht man vom Auge in der deutschen und persischen Liebesdichtung des 17. Jahrhunderts, muss man auch von der Vorgeschichte dieser Augen-Blicke reden, einer Vorgeschichte, die sich zusammensetzt aus Medizinhistorie, Philosophiegeschichte und nicht zuletzt theologischer Spekulation - neben der literarischen Tradition natürlich. Dabei muss es im Rahmen dieses Artikels bei ein paar schnellen Hinweisen bleiben, kurzen Erinnerungen, die lediglich den Hintergrund flüchtig skizzieren, vor dem dann das Phänomen des Augen-Blicks in der Lyrik des 17.Jahrhunderts betrachtet wird, die sozusagen die Perspektive ins Bild bringen, auch eine gewisse Tiefenschärfe.

Dass die Liebe eine Krankheit ist, ist uns allen bewusst - auch wenn man die wirkliche passio heute in die Metapher bannt; und dass die Liebe im Auge entsteht, oder zumindest in entscheidendem Masse übers Auge wirkt, können wir wohl aus Erfahrung bestätigen. Fehlt diese, kann sie ersetzt werden durch 
die Lektüre von Autoritäten, von Platon ${ }^{1}$, Aristoteles ${ }^{2}$, über Plotin ${ }^{3}$, Augustinus, Rhazes/ar-Râzî, Avicenna/Ibn Sînâ, Averroes/Ibn Rushd, dann Andreas Capellanus $^{4}$, bis hin zu Marsilio Ficino ${ }^{5}$ und Robert Burton ${ }^{6}$ - um in den Grenzen des hier betrachteten Zeitraums zu bleiben. Ist die Liebe eine Krankheit, ist das Auge der Ort der Infektion. Dass die Liebe aber eine Krankheit ist, ein Leiden - und zwar im physischen Sinn - ist eine Vorstellung, die in der Seelenlehre des Aristoteles zum ersten Mal systematisch erfasst, unter dem

1 „Die Neigung ( $\check{\rho} \rho \omega \sigma)$ ferner, weil diese Bewegung von aussen hineingeht ( $(\varepsilon \sigma \rho \varepsilon \tilde{\imath})$ und nicht einheimisch (oi $\varepsilon \tilde{i} \alpha$ ) ist bei dem, der sie hat, sondern erst aufgenommen durch die Augen, ist von diesem Eingehn anfangs Hineingehung genannt worden, jetzt aber sagt man mit Wegwerfung des Anfangs und Zusammenziehung des Letzten, und indem man das n vor dem g verschluckt, Neigung ( $\check{\rho} \rho \omega \sigma)$ " (Platon, Kratylos, Sämtliche Werke in zehn Bänden, hrsg. Karlheinz Hülser, insel taschenbuch 1403, Frankfurt/M, Leipzig 1991, III, 420 a/b).

2 „So darf das Wohlwollen als Anfang der Freundschaft gelten, wie es für die sinnliche Liebe die Lust des Sehens ist. Denn niemand liebt, ohne sich zuvor an der Gestalt (des Geliebten) entzückt zu haben. Aber wer sich an der Gestalt (eines anderen) freut, ist deswegen noch keineswegs ein Liebender: dies wird er erst dann, wenn er nach dem Abwesenden Sehnsucht hat und seine Nähe begehrt" (Aristoteles, Nikomachische Ethik, übers. Franz Dirlmeier, Darmstadt 1956, IX, Kap.5, 1167a). Entsprechend sieht Aristoteles das Auge als Thron und Quelle der Liebe (Aristoteles, Nikomachische Ethik, IX, Kap.12, 1171b).

3 „....aus der Kraft nun, die angespannt auf das Geschaute gerichtet war, und aus dem was gleichsam aus dem Geschauten erfloss, entstand wohl eben der Eros als ein ersättigtes Auge, gleichsam ein Sehen das sein Bild schon in sich trägt; von da stammt wohl auch sein Name, weil er nämlich aus dem Schauen (oras-) zu Stande gekommen ist" (Plotin, Enneaden, Plotins Schriften, übers. Richard Harder, V, Die Schriften 46-54 der chronologischen Reihenfolge, Meiner Philosophische Bibliothek 215a, Leipzig 1937, III, Tract.5 c.2, 97).

${ }^{4}$ Andreas Capellanus beginnt seine drei Bücher über die Liebe mit der Feststellung: „amor est passio quaedam innata procedens ex visione et immoderata cogitatione formae alterius sexus" (Andreas Capellanus, De amore libri tres, hrsg. E. Trojel, 2. unver. Nachdruck, München 1972, Lib.1, Cap.1, 3).

${ }^{5}$ Z.B.: „Die Menschen unterliegen dann am meisten dem Zauber, wenn sie häufig die Blicke scharf auf die Augen anderer richten und so beider Licht vereinigen; mit dem Lichte saugen sie ja jämmerlich die Liebe ein. Das Auge ist stets die Ursache und der Ursprung, wie Musaios sang " (Marsilio Ficino, Über die Liebe oder Platons Gastmahl, übers. Karl Paul Hasse, hrsg. Richard Blum, 3. Aufl., Meiner Philosophische Bibliothek 368, Hamburg 1994, Or.VII, Cap.10, 343).

${ }^{6}$ Mit Verweis auf Plotin schreibt Burton: „Die bekannteste und verbreitetste Ursache der Liebe aber ist der Anblick, der jene herrlichen Strahlen der Schönheit und Anmut ins Herz sendet. Plotinus leitet darum die Liebe ab vom Anschauen: $\check{\varepsilon} \rho \omega \sigma$ quasi ö $\rho \alpha \sigma \imath \sigma$. Die Augen sind die Vorboten der Liebe, Anschaun tut den ersten Schritt; sie sind wie zwei Schleusen und lassen die Einflüsse jener göttlichen, mächtigen, seelraubenden und bezwingenden Schönheit eindringen, ,die schärfer ist als Dolche und Degen und tiefer ins Herz dringt und uns durch die Augen liebliche Wunden schlägt, so die Seele selber durchbohren “" (Robert Burton, Schwermut der Liebe, übers. Peter Gan, Manesse Bibliothek der Weltliteratur, Zürich 1992, 117). 
Einfluss von Galen dann seit dem 4.Jahrhundert ganz in den Interessebereich der Medizin rückt, so dass das Kapitel über die Liebeskrankheit zum festen Bestandteil medizinischer Abhandlungen wird. ${ }^{7}$ Es ist hier nicht der Ort, diese Tradition der Liebeskrankheit nachzuzeichnen, eine Tradition, die sich über byzantinische $e^{8}$ und dann arabische Vermittlung ins lateinische Mittelalter zog, wobei man der arabischen Rezeption und Weiterführung unter anderem die Definition dieser Krankheit als eine Krankheit des Gehirns und eine Spielform der Melancholie verdankt. Deutlich ausgesprochen findet sich diese Verknüpfung erstmals bei Rhazes/ar-Râzî (ca. 850-923/24). ${ }^{9}$

Für die europäische Rezeption dieser Krankheit entscheidend waren aber vor allem die Übersetzung von Avicennas/Ibn Sînâs al-Qânûn fî l-tibb (Canon

\footnotetext{
${ }^{7}$ Vgl. dazu Donald A.Beecher, Massimo Ciavolella, Jacques Ferrand. A treatise on lovesickness, New York 1990, $44 \mathrm{ff.:} \mathrm{"It} \mathrm{was} \mathrm{Aristotle,} \mathrm{however,} \mathrm{who,} \mathrm{through} \mathrm{his}$ natural philosophy, gave a systematic form to the concept of erotic passion as disease. The fundamental axiom of his psychophysiological approach is that sensation is a

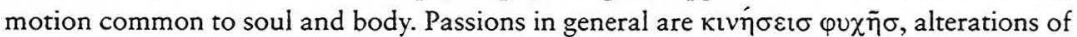
the senses through which the intellect moves the body, and are divided into two groups: mental and somatic perturbations. ... To the second group belong the $\sigma \omega \mu \alpha \tau \iota \kappa \dot{\alpha} \pi \dot{\alpha} \theta \eta$, namely those passions that, like eros, originate in the body and also have a deep influence upon the mental constitution of the individual. Aristotle defines eros as a desire for reproduction. As for its physiological cause it consists, just like anger, in a boiling of the blood around the heart.

Aristotle thereby places the causes of love more firmly in the body, assigning to the heart and reproductive organs more central roles in the generation of erotic appetites. According to a definition found in a fragment of the Aristotelian treatise Eroticos preserved in Abû l 'Alî ben Muhammad al-Daimali's [sic!] Al ma'tuf (eleventh century), eros is born in the heart and from there flows throughout the body...." [Es handelt sich wohl eher um Abû l-Hasan 'Alî Ibn Muhammad ad-Dailamî († nach 982) und dessen Werk Kitâb 'Atf al-alif al-ma'lûf 'alâ l-lâm al-ma'tûf; vgl. Carl Brockelmann, Geschichte der arabischen Litteratur, 2 Bde., 2.Aufl., Leiden 1943-1949, 3 Suppl., Leiden 1937-1942, Suppl. I, 359]. (Die Umschrift der arabischen Schrift verzichtet auf diakritische Zeichen mit Ausnahme der Bezeichnung des Langvokals.)

Dank der Autorität von Aristoteles ist auch das Herz nie mehr ganz aus der Diskussion um die Liebesleidenschaft auszuschliessen, obwohl das Augenmerk später vor allem auf das Hirn sich richtete. Vgl. Beecher und Ciavolella (Anm. 7), 45 f. Vgl. Aristoteles: „Dass nun bei den sinnlichen Wesen der Anfang der Wahrnehmung von demselben Teile kommt wie der Anfang der Bewegung, ist früher an anderer Stelle erklärt worden. Diesen Anfang umfasst aber von den drei zu unterscheidenden Orten derjenige, der zwischen Kopf und Unterleib liegt. Das ist nun bei den Bluttieren die Gegend um das Herz. Denn alle Bluttiere haben ein Herz, und im Herzen liegt der Anfang und Ausgang der Bewegung und der eigentlichen und grundlegenden Wahrnehmung " (Aristoteles, Von Schlafen und Wachen, Kleine naturwissenschaftliche Schriften [Parva naturalia], übers. Eugen Rolfers, Meiner Philosophische Bibliothek 6, Leipzig 1924, 456a, 1-7, 54).

${ }^{8}$ Wie: Paulos von Aigina (7.Jh.), Oreibasios (325-403), u.a.

${ }^{9}$ Rhazes verweist dabei auf das Kitâb al Mâlikî des 'Alî al-Abbâs al-Majûsî, alias Haly Abbas (Mitte 10.Jh.), in dem im 7.Kapitel von der Liebeskrankheit gehandelt wird und diese schon sehr nah mit der Melancholie in Verbindung gebracht wird.
} 
medicinae) durch Gerhard von Cremona Mitte des 12. Jahrhunderts ${ }^{10}$ und ein kleines Büchlein eines gewissen Ibn al-Djazzâr († ca. 1004), seines Zeichens Arzt und Seepirat ${ }^{11}$, das Constantinus Africanus unter dem Titel Viaticum peregrinantis übersetzte und in dem der geschichte-machende Begriff des ,amor hereos' zum ersten Mal auftaucht, als Übersetzung der krankhaften Liebe. Constantinus Africanus war es, der durch seine Übersetzungen arabischer Werke Salerno zum Zentrum medizinischer Forschung seiner Zeit machte. Hier, in Salerno, scheint somit der Anfang der Geschichte der europäischen Liebesmelancholie zu liegen, der Anfang des passionierten Blicks. ${ }^{12}$

So wird also das Auge, der Blick, der Augen-Blick zum wissenschaftlichen Anfang der Liebe, zur Wurzel der Krankheit, in der man eine Spielform der Melancholie erkannte. Und die Wirkung des Blicks wird zur medizinisch fassbaren Grösse.

Die Symptome der Liebskrankheit, die maliziös genau im Detail beschrieben werden, haben alle ihre mehr oder weniger direkte Abhängigkeit vom Auge. Z.B. dringt der Blick des geliebten Menschen als Sehstrahl - auf dem nicht zuletzt auch spiritus, sozusagen vergeistige Körpersäfte sitzen - über das Auge des Liebenden in dessen Körper ein, erhitzt da die Säfte, wodurch schliesslich das Hirn austrocknet und die Urteilskraft, die vis aestimativa, zerstört wird. ${ }^{13}$

Es kann hier nicht auf die verschiedenen wunderbaren Möglichkeiten der physischen Wirkung des Blicks eingegangen werden. Wichtig ist aber festzuhalten, dass hinter den Metaphern des Liebesblicks, des ganzen Liebesgeschehens, wie sie die Dichtungen füllen, fast immer konkrete medizinische Vorstellungen zu finden sind, die diese Metaphern inspirierten. Anderseits und das ist das Faszinierende - wurde das medizinische Denken wieder durch

\footnotetext{
${ }^{10} a l$-Qânûn fî l-tibb; vollständig übersetzt von Gerhard von Cremona zwischen 1150-1187. Später noch mehr als 87 weitere Übersetzungen. Avicenna nennt das Leiden al-'ishq, was verlateint dann zu alhasch wird.

${ }^{11}$ Ibn al-Djazzâr, Zâd al-musâfirîn. Übersetzung ins Hebräisch und Lateinisch. Vgl. Gerhard Endress, „Die wissenschaftliche Literatur“, in: Helmut Gätje (Hrsg.), Grundriss der arabischen Pbilologie, II. Literaturwissenschaft, Wiesbaden 1987, 400-506, hier: $446 \mathrm{f}$.

${ }^{12}$ Neben einem Überfluss an Körpersäften, die zur Entladung drängen und dadurch den sexuellen Trieb stimulieren, wurde der Anblick eines begehrenswerten Objekts als verhängnisvolle Ursache dieser Krankheit erkannt. Die Absurdität einer solchen Herauslösung eines beliebigen Einzelobjekts zum Non plus ultra konnte man sich aber nicht anders als durch eine Defizienz der Urteilskraft erklären, der vis aestimativa. Aristotelische Tradition und medizinische, galenische Überlieferung schlossen sich da zu einem neuen Kreis zusammen.

${ }^{13}$ Beecher und Ciavolella (Anm. 7), 77 und 81.

Vgl. dazu: M. Ficino (Anm. 5), Or.VII, Cap.4, 323. Was nicht heisst, dass diese Vorstellungen nicht auch diskutiert und z.T. verworfen wurden in der Renaissance. Vgl. z.B.: Der dritte Kommentar Lorenzo Ghibertis, eingeleitet, kommentiert und übersetzt von Klaus Bergdolt, Weinheim 1988, 198 und 199, Anm. 5 und 6.
} 
die poetischen Metaphern beeinflusst. Ganz von Anfang an waren es auch poetische Texte, die für medizinische Erkenntnisse und Aussagen als Quellen und Beweise herangezogen wurden, finden sich in medizinischen Abhandlungen zum Thema Dichter und Dichterinnen als Autoritäten zitiert. So zieht sich durch die ganze wissenschaftliche Tradition eine Kette von ver-dichteten Symptomen der Liebeskrankheit, von Sappho und Archilochus bis Petrarca und Ronsard. Man hat also das wunderliche Phänomen einer Metaphorik der Liebe, die über ihre Bildhaftigkeit die wissenschaftliche Erkenntnis verführt, gleichzeitig sich aber in dieser verführten Erkenntnis neu bildet. Ein Teufelskreis, in dessen Mitte, dessen totem Punkt, sich das gesuchte Phänomen versteckt, das, was letztlich ineffabile bleibt. ${ }^{14}$

All diese Vorstellungen bildeten sich im Zusammenspiel von antiker und arabischer Wissenschaft und ihrer europäischen Rezeption. Liebeskrankheit und pathologisierter Blick nahmen sozusagen ihren Anfang in der Begegnung von Ost und West. ${ }^{15}$ Und natürlich war es nicht nur die wissenschaftliche Literatur, die die Brücke schlug zwischen arabischer und europäischer Liebestheorie. Es lässt sich vermuten, dass auch direkte Kenntnis arabischer Werke anderer Literaturgattungen westliche Autoren beeinflusst hat. Wahrscheinlich ist dies für Andreas Capellanus, in dessen Werk De amore libri tres direkte Anlehnungen an Ibn Hazms Tauq al-Hamâma (Das Halsband der Taube) gesehen werden können. ${ }^{16}$ Ganz zu schweigen vom Liebeskonzept der Trobadors, wo ein Einfluss spanisch-arabischer Hofkultur angenommen werden muss.

Hier soll aber nicht dieses Netz von gegenseitiger Beeinflussung interessieren, sondern die paar wenigen Hinweise müssen genügen, um zu zeigen, dass Ähnlichkeiten im Liebesdiskurs in der deutschen und persischen Dichtung des 17.Jahrhunderts nicht zufällig sind, das Spiel der Gegenüberstellung einen gewissen Ernst hat.

Gefragt werden soll also nicht nach der Gleichheit, sondern nach den Unterschieden. Sowohl in der europäischen Literatur wie in der persischen gibt es ein Liebeskonzept, in dem die Liebeskrankheit, das Leiden des Liebenden im

\footnotetext{
${ }^{14}$ Dazu gehört auch, dass lange bevor in den medizinischen Traktaten Feuer und Blitz Amors ihre medizinische Entsprechung in Hitze und Sehstrahl fanden, Amor diese Attribute mit sich trug. Seit dem 4.Jh. v. Chr. wird Amor mit Pfeil und Bogen dargestellt, vorher nur mit Flügeln. Seit dem 3.Jh. v. Chr. ist sein festes Attribut das Feuer. Vgl. Lothar Freud, "Amor, Amoretten“, Reallexikon der deutschen Kunstgeschichte, München 1983 ff., I (1983), 641-651.

15 Wenn ich hier von arabischer Wissenschaft spreche, meint dies die theoretische und wissenschaftliche Literatur des islamischen Raumes des Mittelalters. Der persische Raum ist somit eingeschlossen. Ibn Sînâ/Avicenna stammte ja aus dem östlichen Iran.

${ }^{16}$ Vgl. dazu: Leo Pollmann, Der Tractatus De Amore des Andreas Capellanus und seine Stellung in der Geschichte der Amortheorie, Freiburg i.Br. 1955 (Diss. Masch.).
} 
Zentrum steht, ja, die Liebe sich erst über die Qualen des Liebenden definiert. Es ist das Konzept des überhöhten, unnahbaren Geliebten, der grausam die Distanz wahrt und vor dem sich der Liebende zum Sklaven stilisiert, der seine höchste Lust im Tod findet. Es ist das, was bei uns gemeinhin unter dem Begriff des Petrarkismus mit seinem Schlagwort ,dolendi voluptas` verstanden wird, was als Phänomen aber eben auch die persische Literatur prägt.

Dabei beruht das erotische Spiel, das in dieser Dichtung entstehen kann, nicht zuletzt auf der Paradoxie der vollkommenen Entkörperlichung und Sublimierung ins geistreiche Sprachspiel eines an sich im Körper lokalisierten Geschehens. Das Erotikon dieser Dichtung hat nichts zu tun mit handgreiflicher Körperlichkeit, sondern es ist im wahrsten Sinn Lese-Lust. Es ist Selbstbefriedigung eines einsamen Geistes, das körperliche Du hat sich in den Metaphern verflüchtigt. Das Du im Gedicht ist nur Spiegel des Ich, notwendiges Scheingegenüber, an dem das Ich erotisiert werden kann, wobei die Spielregeln, wie gesagt, aus der Medizin bekannt sind. Es geht also um das Phänomen der Erotisierung, der Erotik der Phantasie und nicht um das Phänomen der Liebe als einer zwischenmenschlichen Beziehung, auch nicht um das Phänomen kruder Sexualität.

Vieles, was zu dieser Dichtung, der westlichen und der östlichen, gesagt wurde, krankt m.E. daran, dass man trotz allen Bewusstseins ihrer Andersartigkeit die reine Artifizialität da, wo es um ,Liebe' geht, nicht ganz gelten lässt. Man sucht nach der greifbaren Wirklichkeit in der Meinung, dem Thema anders nicht gerecht zu werden. ${ }^{17}$

Das Auge nun, Organ der Distanz, aber auch "Thron und Quelle der Liebe “, wie Aristoteles sagt, ist Schauplatz par excellence dieses erotischen Spiels des Intellekts, das nicht selten auch Spiel des Intellekts mit der Erotik ist. Im folgenden soll versucht werden, diesen Spielereien nachzuspüren, in Ost und West und im feinen, aber umso entscheidenderen Unterschied.

Spricht man vom Auge in der deutschen und persischen Liebesdichtung des 17.Jahrhunderts, ist zwischen dem Auge der Geliebten, beziehungsweise des Geliebten und dem des Liebenden - und hier ist die maskuline Form allein gültig - zu unterscheiden. Denn eine Gleichheit in Funktion und Wirkung, d.h. eine Gleichartigkeit der Augenfunktion, wie z.B. in Georg Rodolf Weckherlins Sonett Lieb gegen Lieb, gibt es selten - vor allem in der deutschen Literatur.

\footnotetext{
${ }^{17}$ Dass schon die Zeit selber den Abstand zwischen greifbarer Realität und Realität des Wortes sah, zeigen ironisierende, parodierende Zeugnisse wie die berühmte „Karikatur" La belle Charite, das getreue Abbild einer erdichteten Geliebten von M. Van Lochem nach Crispin de Passe.
} 
Lieb gegen Lieb ${ }^{18}$

Demnach mich Amor selbs nunmehr ein lange Zeit Gezüchtiget / vnd recht zu kriegen vnderrichtet /

Hat endlich sich mein muht mein lang-erwünschte beut /

Oder den schönsten tod zu erwerben / verpflichtet.

Darumb als in dem feld sich Myrta nicht mehr weit Von mir forchtloß befand / vnd newe list erdichtet / $\mathrm{Hab} /$ wie sie wider mich / ich wider sie / den streit Anfangend / die geschoß der anblick stracks gerichtet.

Das treffen war sehr groß. Dan jhrer augen blick Nicht nur wie pfeil vnd plitz / sondern wie grosse stück Zerschmetterten mein hertz / vorhin voll taussent wunden

Endlich hat meine kunst vnd müh den weeg gefunden / $\mathrm{Daß}$ wie mein / so jhr hertz / numehr mit gleichem glick Verwundet / sich ergab / sigreich vnd überwunden.

Hier wird der Liebende von Amor höchstpersönlich zum Krieger ausgebildet, indem er ihn quält und drillt, bis er sich schliesslich bereit erklärt, aufs Ganze zu gehen, sich seiner Myrta wehrhaft auf Tod und Leben gegenüberzustellen. Dabei ist das „Oder" des vierten Verses concettistisch doppelsinnig. Denn einerseits kann man es disjunktiv lesen im Sinne von ,Leben oder Tod des Kriegers, anderseits hat es eine kopulative Funktion, wo der „schönste Tod" sich erklärend neben den Erwerb der "lang-erwünschte(n) beut" stellt und so den pikanten und eindeutigen Sinn der piccola morte erhält. Und darin, in diesem pikanten Doppelsinn, fallen die metaphorische Ebene des Kriegstreffens und die scheinbar eigentliche Ebene der Liebesbegegnung zusammen. Darin hat die Sprache ihr reales Ziel und wird die alte Allegorie des Liebeskriegs von der Realität eingeholt.

Das alles nun aber spielt sich in den Augen ab. In ihnen konzentriert sich das Geschehen, wie sie auch das Zentrum des Gedichtes sind: die Blicke treffen und verschränken sich chiastisch genau in den zwei Mittelversen des Sonetts. Nur weil Myrta sich ihrer zu sicher wähnt und "forchtloß" in der Nähe des Liebenden sich aufhält, gelingt die Gegenattacke des von Amor ausgebildeten Schützen. In einem letzten grossen Treffen stehen sich die zwei Gegner gegenüber, im wahrsten Sinne Aug in Aug, und somit in der gefährlichsten Position, vor der seit alters gewarnt wird, da so der Augenstrahl ungehindert und direkt ins Herz des Gegenüber dringen und da übel wüten kann. ${ }^{19}$ Dabei wird - in

\footnotetext{
${ }^{18}$ G.R.Weckherlin, Gedichte, ausgew. und hrsg. Christian Wagenknecht, Reclam Universal-Bibliothek 9358-60/60a, Stuttgart 1972, 207.

${ }^{19}$ Vgl. Marsilio Ficino (Anm. 5), Or.VII, Cap.10, 343: „Auf welche Weise die Liebenden bezaubert werden, haben wir vorhin zur Genüge erörtert. Nur ist zu dem Gesagten
} 
Steigerung des Bildes - die ursprüngliche Vorstellung des Augenblitzes, des Pfeils, der aus dem Auge schiesst, als Amors klassische Waffe, in, fast möchte man sagen modischer Art, ergänzt, indem die Augen dieser Myrta nicht nur Pfeile schiessen, sondern wie Kanonen („grosse stück“) das Herz des Liebenden nicht nur verwunden, sondern zerschmettern. War das Herz vorher „voll taussent wunden ", so zersplittert es jetzt vollkommen - und erwirbt sich so den "schönsten tod“.

Das „Endlich“ der Schlussterzine nimmt somit das Geschehen des vorhergehenden Verses auf, den Schlusspunkt dieses Treffens, verweist gleichzeitig aber

noch folgendes hinzuzusetzen: Die Menschen unterliegen dann am meisten dem Zauber, wenn sie häufig die Blicke scharf auf die Augen anderer richten und so beider Licht vereinigen; mit dem Lichte saugen sie ja jämmerlich die Liebe ein. Das Auge ist stets die Ursache und der Ursprung, wie Musaios sang. Darum zwingt eine Person mit anmutig leuchtenden Augen, wenn sie auch in übriger Hinsicht nicht wohlgestaltet ist, dennoch den, welcher sie anblickt, zur Liebe. Die gegenteilig beschaffene Person hingegen regt eher zu mässiger Neigung als zu Liebe an."

Burton zitiert dieselbe Stelle: „Sterbliche unterliegen diesem Zauber besonders dann, wenn sie einander häufig anstarren und dabei in die Augen blicken und so gegenseitige Liebe aus sich trinken und saugen; denn der Anfang dieser Krankheit ist das Auge; daher jemand, der helle Augen hat, er sei sonst auch missgestaltet, so bindet er doch denjenigen, der ihn häufig anschaut fest an sich durch die Augen und bringt ihn um seinen Verstand“ (Robert Burton [Anm. 6], 137).

Und an anderer Stelle sagt Marsilio Ficino: „Ist es demnach zu verwundern, dass, wenn das geöffnete und mit Aufmerksamkeit fest auf jemand gerichtete Auge nach den Augen des Beschauers die Pfeile seiner Strahlen schnellt, es zugleich mit diesen, welche das Vehikel der Lebensgeister [spirituum vehicula] sind, den Blutdunst ausströmt, welchen wir Lebensgeist nennen? Von dort dringt der giftige Pfeil in die Augen ein, und weil er vom Herzen dessen, der ihn abschiesst, ausgeht, dringt er in das Herz des Getroffenen, also gleichsam in die ihm eigentümliche und angestammte Gegend ein. Alsdann trifft er das Herz, verdichtet sich auf dessen fester Oberfläche und wird wieder zu Blut. Dieses fremde Blut, welches doch nicht zur Natur des Getroffenen gehört, trübt dessen eigenes, und das getrübte, sozusagen angesäuerte Blut wird krank" ([Anm. 5], Or.VII, Cap.4, $325 \mathrm{f}$.).

Vgl. auch die Stelle im Phaidros von Platon: „... und wie ein Wind oder ein Schall von glatten und starren Körpern abprallend wieder dahin, woher er kam, zurückgetrieben wird, so geht auch die Ausströmung der Schönheit wieder in den Schönen durch die Augen, wo der Weg in die Seele geht, zurück, und wenn sie dort angekommen, befeuchtet sie reichlich die dem Gefieder bestimmten Ausgänge, treibt so dessen Wachstum, und erfüllt auch des Geliebten Seele mit Liebe. Er liebt also, wen aber weiss er nicht, ja überhaupt nicht was ihm begegnet weiss er oder kann er sagen, sondern wie einer, der sich von einem Andern Augenschmerzen geholt, hat er keine Ursache anzugeben; denn dass er wie in einem Spiegel in dem Liebenden sich selbst beschaut, weiss er nicht. Und wenn nun jener gegenwärtig ist, so hat auch er gleichwie jener Befreiung von den Schmerzen, ist er aber abwesend, so schmachtet auch er wie nach ihm geschmachtet wird, mit der Liebe Schattenbilde, der Gegenliebe, behaftet “ (Platon, Phaidros, Sämtliche Werke in 10 Bänden, hrsg. Karlheinz Hülser, insel taschenbuch 1406, Frankfurt/M, Leipzig 1991, VI, 255c,d). 
auch auf die vereinigende Schlussstrophe, wo die zwei Kämpfer sich "nunmehr mit gleichem glick verwundet" ergeben und Sieg und Niederlage zusammenfallen.

Das zitierte Beispiel der zurückschiessenden Augen des Liebenden bei Weckherlin ist, wie gesagt, eine Rarität. Denn in der Regel ist - vor allem in der deutschen/europäischen Dichtung - nur vom Auge der Geliebten die Rede und von seinen Auswirkungen auf den Zustand des Liebenden, wenn nicht, sozusagen in einer eigenen lyrischen Gattung, die eigenen Tränen bedichtet werden. Davon aber später.

Zunächst zu einem anderen Gedicht von Weckherlin.

Von jhren überschönen Augen ${ }^{20}$

Jhr Augen / die jhr mich mit einem Blick und Plitz

Scharpf oder süß nach lust könt strafen vnd belohnen;

O liebliches Gestirn / Stern / deren liecht und hitz

Kan / züchtigend den stoltz / der züchtigen verschonen:

Vnd jhr / der Lieb werckzeug / kundschaffter vnsrer witz /

Augbrawen / ja vilmehr triumfbogen / nein / Cronen /

Darunder Lieb vnd Zucht in überschönem sitz

Mit brauner klarheit schmuck erleuchtet leuchtend wohnen!

Wer recht kan ewre form / farb / wesen / würckung / krafft /

Der kan der Engeln stand / schein / schönheit / thun vnd gehen /

Der kan der wahren Lieb gewalt vnd eigenschafft /

Der Schönheit schönheit selbs / der sehlen frewd und flehen /

Vnd der Glickseeligkeit vnd Tugenten freindschafft

In Euch (der Natur kunst besehend) wol verstehen.

Vieles hier ist Topos: Der Blitz des Auges, der bittersüss und willkürlich straft und belohnt, der Augen-Stern, dessen Licht und Hitze züchtigt, die Brauen, die, als Amors-Bogen, „der Lieb werckzeug" sind und als „kundschaffter unsrer witz" im Hirn des Liebenden herumspionieren, ${ }^{21}$ auch ihre Klimax zu Triumphbogen und Krone über dem blitzenden Auge und dessen „braune Klarheit“.22

${ }^{20}$ G. R.Weckherlin (Anm. 18), 203.

${ }^{21}$ André Du Laurens (1558-1609) schreibt in seinem Werk Des maladies melancholiques, et du moyen de les guarir, ch.10, p34v: „L'amour doncques ayant abusé les yeux, comme vrays espions et portiers de l'ame, se laisse tout doucement glisser par des canaux, et cheminant insensiblement par les veines jusques au foye, imprime soudain un desir ardent de la chose qui est, ou paroist aimable, allume ceste concupiscence, et commence par ce desir toute la sedition.. " - Zitiert nach: Beecher und Ciavolella (Anm. 7), 416, Anm. 1. Ferrand übernahm diese Stelle fast wörtlich in seiner Abhandlung.

22 So schreibt z.B. auch Burton mit Bezug auf die Bibel und die Antike wie selbstverständlich: „Von allen Augen sind (nebenbei) die schwarzen die schönsten und bezau- 
Dabei gehen diese Versatzstücke der Schönheit, so eingefroren sie sich in der dichterischen Tradition präsentieren, auf das gelebte modische Schönheitsideal der italienischen Renaissance zurück, wo man die Brauen zu einer feinen Linie zupfte und schwarz färbte, die Augenwimpern aber ausriss, um das dunkle Auge in seiner Nacktheit zu präsentieren. Maskara kam erst im 18.Jahrhundert auf. ${ }^{23}$ Es ist dieses Ideal, das auch noch die deutsche Dichtung des 17.Jahrhunderts bestimmt, dieses Ideal, dem die hier betrachteten Augen zugehören. Deshalb kommt auch kein Dichter auf die Idee, die Wimpern zu beschreiben, eine Eigentümlichkeit, die man normalerweise überliest, die aber gerade im Vergleich mit der persischen Dichtung auffällt, wo in den Wimpern ein zentrales erotisches Moment steckt.

Eine mehr oder weniger langweilige Anhäufung traditioneller Klischees also? Die genaue Lektüre belehrt eines besseren:

Die Augen, diese „überschönen Augen“, auf deren Epitheton am Schluss zurückzukommen ist, werden, herausgelöst aus dem Körper der Geliebten, zum Augenbildchen ausgeschnitten, ${ }^{24}$ direkt angesprochen. Als „Augen“ zunächst, in ihrer Materialität als Sehorgan der Geliebten, dann, als „liebliches Gestirn, Stern“, in den Makrokosmos gespiegelt, um dann als „überschöner sitz" von "Lieb und Zucht" auf die Engel und schliesslich Gott selbst hinzuweisen. In ihrer Eigenschaft als "Augen“ "strafen und belohnen“ sie "nach lust“, d.h. willkürlich, sind sie Werkzeug des Eros, wobei der Blick süss belohnt, der Blitz scharf bestraft. Im Blick, der den Lohn einschliesst, lösen sich Marter und Leiden auf und fallen diese Augen aus dem streng petrarkistischen Konzept heraus - wenn dieses unter dem Schlagwort der dolendi voluptas gefasst ist. Nur im Blitz, da, wo die Augen sich in der Metapher typisierend verwandeln, passen sie sich in den Topos ein.

Und genauso nachher, wenn das Licht des Augensterns verschont, seine Hitze aber züchtigt. ${ }^{25}$ Dabei ist selbst in dieser züchtigenden Hitze - wie auch im strafenden Blitz - keine sinnlose Quälerei, fehlt die ziellose Grausamkeit.

bern am meisten; nigra oculos formosa mihi, ein schwarzäugiges Mädchen dünkt mich am schönsten. Homer gebraucht für Juno das Beiwort ,ochsenäugig', weil runde schwarze Augen am meisten und helle graue Augen am wenigsten gefallen..." (Robert Burton [Anm. 6], 136).

${ }^{23}$ Vgl. Sara F.Matthews Grieco, „Körper, Äussere Erscheinung und Sexualität“, in: Georges Duby, Michelle Perrot (Hg.), Geschichte der Frauen, 5 Bde., III: Frühe Neuzeit, hrsg. Arlette Farge, Natalie Zemon Davis, Frankfurt/M 1994, 61-101, hier: 77.

${ }^{24}$ Die Preziose des sogenannten Augenportraits kam dann um 1800 in Mode. Vgl. Astrid Schmidt-Burkhardt, Sehende Bilder. Die Geschichte des Augenmotivs seit dem 19. Jabrhundert, Berlin 1992.

${ }^{25} \mathrm{M}$. Ficino schreibt in bezug auf die Wirkung der Liebe auf den Liebenden: „Abwechselnd fühlen sie Kälte und Hitze wie die am Wechselfieber Leidenden. Kälte fühlen sie naturgemäss, weil sie ihre eigene Wärme einbüssen; Hitze spüren sie, da sie vom Blitze des überirdischen Lichtglanzes entzündet werden“ ([Anm. 5], Or.II, Cap.6, 59). 
Vielmehr wird hier ein Vergehen geahndet, das im Horizont einer höheren Instanz als solches definiert ist. Die Schuldlosen, diejenigen, die sich schon selbst gezüchtigt haben, werden denn ja auch verschont, sind aber - um es umgekehrt auszudrücken - auch von der Passion im Sinne der Leidenschaft unberührt. Die Passion, das Leiden, wird hier in einen Bereich der Zuchtlosigkeit gebannt, einen Bereich, wo der Stolz des Liebenden die quälende Hitze im Auge der Geliebten provoziert, wogegen der Züchtige, was hier soviel wie der Nicht-Stolze, also auch: Demütige heisst, das Licht im Auge der Geliebten schaut. In Marsilio Ficinos Kommentar zu Platons Symposium von 1469 liest man:

Das Gute ist die hervorragende Wesenheit Gottes. Die Schönheit ist eine Wirkung oder ein Lichtstrahl, welcher, von ihm ausgehend, alles durchdringt: zuerst den Engelsgeist, zweitens die Allseele und die Einzelseelen, drittens die Natur, viertens die Materie der Körper. ...Und wie ein jeder, welcher in jenen vier Elementen das Licht sieht, den Sonnenstrahl erblickt und durch ihn veranlasst wird, zu dem erhabenen Sonnenlicht selbst aufzuschauen, ebenso schaut und liebt ein jeder, der die Herrlichkeit in diesen vier, nämlich Geist, Seele, Natur und Materie betrachtet und liebt, in jenen den Lichtstrahl Gottes und durch ihn Gott selber. ${ }^{26}$

Das ist das erleuchtete Leuchten dieses Auges. Und ganz neu sinnvoll wird da auch die scheinbar abgegriffene Metapher des Sterns für das Auge. Es ist nicht einfach topisch der Sternenglanz, der mit dem Auge zusammengebracht wird, sondern so, wie der Stern ein reflektierender Körper ist, ist das Auge nur Abglanz, nur Reflex göttlichen Lichts.

Ist das blitzende Auge das erotisierte Auge, das entzündende Auge, in dem Eros mit seinen Pfeilen hockt, ist das Auge, in dem die Zucht neben der Liebe wohnt, das lichtvolle Auge, in dem sich Gott manifestiert. Eine Entkörperlichung des Eros, die in engstem Zusammenhang steht mit dem Denken des Neuplatonismus. So wird hier das Auge zum Altar von Liebe und Tugend, gekrönt von den Augenbrauen, die in ihrer Eigenschaft als „werckzeug“ der Liebe noch an den Bogen Amors anklingen, dann aber, zu Triumphbogen und Krone gefroren, sich ganz zurücknehmen aus jeder Dynamik, die dem Bild noch einen letzten Hauch von Erotik geben könnte. Die Liebe als passio, als Krankheit, verliert hier ihren sinnlichen Spielgrund. Die Schönheit selber, dieses Erotikon par excellence, wird, als Kunststück der Natur, als Preziose der Schöpfung, zum Zeichen Gottes, der „wahren Lieb“27, der „Schönheit schön-

\footnotetext{
${ }^{26}$ M. Ficino (Anm. 5), Or.II, Cap.5, $55 \mathrm{f}$.

${ }^{27}$ Die Unterscheidung zwischen einem amor verus und einem amor fatuus, einem amor carnalis und einem amor coelestis ist eigentlich augustinische Umformung platonischen Gedankenguts.
} 
heit selbs“28. Es geht nicht mehr um die physisch erfahrbare Gewalt des Eros, sondern um eine vollkommene Sublimierung ins Geistige, eine Entkörperlichung im extremsten Sinn. ${ }^{29}$ Ficino fasst es so zusammen:

die Schönheit ist ein bestimmter lebensvoller und unkörperlicher Liebreiz, welcher durch den göttlichen Lichtstrahl zuerst dem Engel, dann den Seelen der Menschen und endlich den körperlichen Gestalten und den Tönen eingegossen wird. Dieser Liebreiz erregt durch Vermittlung des Verstandes, des Gesichtes und des Gehörs unsere Seele, reisst sie in der Entzückung fort und begeistert sie im Hinreissen zu glühender Liebe. ${ }^{30}$

Hat am Anfang das Sonett petrarkistische Motivik aufgreifend die Tyrannei der Geliebten thematisiert, mit Metaphern und Epitheta, die ihre erotische Vorgeschichte haben, verflüchtigt sich, gezüchtigt und züchtig, die körperliche Liebe, die Liebe im Körperlichen, zum Schluss ganz in der Überhöhung der Augenschönheit zur „Schönheit schönheit selbs“. Die Potenz dieser Augen - im sexuellen Sinn - wird gebrochen. Der Liebende, zumindest der züchtig Liebende, der „recht“ schaut und „wol“ versteht, ist da nicht mehr gefährdet. Im Gegenteil: auf dem Altar der Augen betet er Gott an, die „wahre Liebe“. Es ist eine Leidenschaft, die nicht krank macht, sondern heilt. Die Augen hier sind eben nicht einfach ,schön', erotisierend, sondern „überschön“, d.h. über das materiell Schöne hinausweisend.

Das Auge der Geliebten hat hier nichts mehr zu tun mit dem Auge einer Geliebten, sondern in seiner Schönheit ist es lediglich Durchblick, Fenster zu einer von jeder Köperlichkeit abstrahierten Erkenntnis der ,pulchritudo absoluta'. Man kann also auch nicht mehr von einem Liebesdiskurs im petrarkistisch erotischen Sinn sprechen, denn dieser wird nur anzitiert, um dann in der Steigerungsform Gefäss theosophischer Spekulation zu sein, auch jenseits jeglicher geschlechtsspezifischer Typisierung.

Ganz anders dann bei Hofmannswaldau, diesem grössten Könner der galanten Dichtung, jener Dichtung, die den Witz - im barocken Sinn -, die geistreiche, intellektuelle Spielerei, auf die Spitze getrieben hat. Bei ihm sind die

\footnotetext{
${ }^{28}$ Dass die „Schönheit der Schönheit“" eine Umschreibung eines göttlichen Attributes ist, wird klar, wenn man den platonischen, resp. neuplatonischen Hintergrund der theologischen Spekulationen der Zeit bedenkt. In der Tradition von Ps.-Dionysius Areopagita und des Boethius wird „pulchritudo absoluta“ als Gottesname verstanden.

${ }^{29}$ Ficino sagt: „Versuche einmal den Stoff zu entfernen, wenn du kannst! In Gedanken kannst du es. Wohlan, nimm von dem Gebäude den Stoff hinweg und lass den Plan bestehen! Dann wird dir von dem materiellen Körper keine Spur übrig bleiben. Hingegen wird der Plan, welcher von dem Meister herstammt, ein und derselbe sein, wie der noch in ihm verbliebene. Nimm nun das gleiche mit dem Körper eines jeden beliebigen Menschen vor! Du wirst finden, dass seine Form, welche mit dem Urbild der Seele übereinstimmt, einfach und stofflos ist" ([Anm. 5], Or.V, Cap.5, 153).

${ }^{30}$ M. Ficino (Anm. 5), Or.V, Cap.6, 159 f.
} 
geliebten Augen "helle Mörderinnen “31 und der "heisse augen-blitz" „verbrennet" ihn „zu aschen “32. Ganz so, wie man es sich petrarkistisch vorstellt. Ein anderes Gedicht geht folgendermassen:

Ich bin verletzt durch deinen augen-strahl /

Der seinen blitz in meine brust getrieben /

Soll / Lesbia / du ursprung dieser qval /

Vergehen nicht mein hertze gantz im lieben;

So halte doch nur einen augenblick

Den strahl zurück.

Wen brennt die nacht der liebes-flamme nicht /

Als die zur glut dem menschen ist erkohren?

Ein gantzes meer lescht nicht ihr schönes licht I

In dessen abgrund Venus ward gebohren /

In wellen schwamm diß schöne ungeheur /

Und bleibt ein feur.

Mein hertz besteht aus wachs und nicht aus eiß /

Ich fühl und seh / wie deine augen blitzen:

Zweyfache glut ist sterblichen zu heiß /

Was wunder / wenn zwo sonnen mich erhitzen /

Die gar der himmel seltner schönheit preist /

Und brennen heist.

Nicht dencke / daß es blosse worte seyn /

Welch hertz kan wohl bey deiner glut erkalten?

Du weist / ich bin kein engel und kein stein /

Ich muß des blutes regung lassen walten /

Die GOtt dem menschen schon im paradieß

Ins hertze bließ.

Drum zürne nicht ob diesem meinem brand /

Der sich aus deiner augen glut entsponnen /

Es ist / mein kind / ein werck von deiner hand /

Ach! dencke nach und straffe deine sonnen /

Aus welchen dieses feur / so in mir glimmt /

Den ursprung nimmt.

So liebe dann was deine krafft versehrt /

Mein niedrig seyn kan deinen ruhm nicht tilgen /

Die sonne bleibet doch in gleichem werth /

${ }^{31}$ IHr hellen mörderin, in: Christian Hofmann von Hofmannswaldau, Gedichte, hrsg. Manfred Windfuhr, Reclam Universal-Bibliothek 8889, Stuttgart 1983, 21.

32 An Melinden, in: Christian Hofmann von Hofmannswaldau (Anm. 31), 25. 
Anders als im Augengedicht von Weckherlin ist hier eine namhafte Geliebte angesprochen - wenn auch in topischer Maskerade -, ein Du. Die Augen sitzen hier in einem Körper, aus dem sie sich nicht ausschneiden lassen, und entsprechend wirken sie auf den Körper des gequälten Ich. War das Gedicht von Weckherlin eine Art Meditation über schöne Augen, die darin eben zu „überschönen “ Augen werden, geht es hier nun ganz deutlich um das durch das Auge der Lesbia verletzte Ich des Sprechenden; wobei der „ursprung dieser qual“", Lesbia selber, hinter dem Ich und dem Augen-strahl zurücktritt und ganz eigentlich erst an dritter Stelle kommt.

Der klassischen Anordnung gemäss verletzt der Augenstrahl der Geliebten den Liebenden und treibt, d.h.: schiesst seinen Blitz in dessen Brust. ${ }^{34}$ Das bekannte Bild, die alte Vorstellung wird hier nun aber in der sprachlichen Realisierung concettistisch zugespitzt durch die Bitte, diesen Augen-Blick einen Augenblick zurückzuhalten. Und durch die paradoxe Absurdität, die im Wort des Augenblicks aufbricht, wird dieser zum verhängnisvollen Liebesblick.

Aber wie gesagt, anders als bei Weckherlin, ist hier der Kreis vom Auge der Geliebten über den Blick ins Herz des Liebenden - und dann wieder ins tränende Auge des Liebenden, geschlossen. Nicht nur aber ist dieser Kreis geschlossen, sondern über ihn definiert sich das sprechende Ich auch in seiner menschlichen Kreatürlichkeit, eine Definition, in die sich die Legitimation des brennenden Eros einschliesst.

Denn die rhetorische Frage am Anfang der zweiten Strophe impliziert eine Antwort, die die sinnliche Liebe als menschliches Attribut bestimmt. Dabei ist mit „nacht der liebes-flamme“ natürlich der brennende Strahl aus dem schwarzen Auge gemeint, ist aber, über die spielerisch in der Metapher eingeschlossene Assoziation, auch die Liebesnacht evoziert. Die dem Menschen auserwählte "glut" ist so nicht nur der Blitz des Augenstrahls, sondern auch die "glut" der sehr viel greifbareren Liebesnacht. Durch die assoziierende Metapher wird sozusagen die Distanz des Blicks aufgehoben und inszeniert sich eine körperliche Nähe im nachtschwarzen Auge der Geliebten.

Dass diese Liebesflamme nun aber nicht zu löschen ist, begründet sich im Mythos. Denn Venus, der Schaumgeborenen, die, als „schönes ungeheur“,

\footnotetext{
${ }^{33}$ In: Christian Hofmann von Hofmannswaldau (Anm. 31), 36.

34 "treiben" ist hier wohl im Assoziationsfeld von "schiessen" zu lesen. Vgl. Grimm, Deutsches Wörterbuch, 33 Bde., Nachdruck München 1991, XXII, 35.
} 
heute noch "schönes licht" und "liebes-flamme" ist, hat das Meer auch nichts anhaben können - sie „bleibt ein feur“. 35

Wenn Hofmannswaldau nun aber das Herz des Liebenden mit Wachs vergleicht, in dem die Augenblitze spürbar Spuren hinterlassen, spielt er mit der letztlich auf Aristoteles und Platon zurückgehenden, weit verbreiteten Idee, dass sich das geliebte Objekt über das Auge in die Vorstellungskraft des Liebenden prägt, wie ein Siegel sein Bild in Wachs drückt. ${ }^{36}$ Der die Antithese antönende Vergleich aber, der negierende Vergleich mit Eis, erinnert an den petrarkistischen Topos des eisigen Herzens der Geliebten. Wenn also das Ich für sich das Wachsherz beansprucht und das eisige Herz verneint, distanziert es sich implizit von einer möglichen Kälte der Geliebten und beruft sich gleichzeitig auf eine ,natürliche' Beschaffenheit seines Körpers, in der sich seine Liebe erklärt. Eine Liebe, die - durch das Netz fest konnotierter Metaphern als Passion gezeichnet - nun himmlisch legitimiert und darin entschuldigt wird. Denn dass die „zweyfache glut“ dieser Augen „sterblichen zu heiß“ ist, heisst nichts anderes, als dass der Mensch in seiner Kreatürlichkeit dazu verdammt oder „erkohren“ - ist, in dieser Glut zu sterben. Sind aber die zwei Sonnen, die diese Doppelglut hervorbringen in ihrer Schönheit vom Himmel auserwählt zu brennen und verbrennen, ist diese Hitze mitsamt ihren Folgen vom Himmel bestimmt, wird die Liebesglut des Liebenden in gewisser Weise geläutert und der Liebestod, in seiner grossen und kleinen Form, himmlisch abgesegnet. Über die Erhöhung der Geliebten wird also die eigene niedere, fleischliche Liebe und Lust entschuldigt.

Dass diese Versternung der Geliebten Topos ist, wird nun gleich thematisiert, um in der Negation dann hyperbolisch überhöht zu werden: Mag ja sonst die Liebesdichtung Wortgedröhn sein, hier, bei dieser Glut, entspricht die Wirklichkeit der gesteigerten Sprache. Gleichzeitig wird so aber auch diese Überhöhung und Distanzierung der Geliebten ins himmlische Objekt über die Sprache, in der sich diese Distanz aufgebaut hat, wieder rückgängig gemacht. Und die „zweyfache glut" der „zwo sonnen“ wird wieder zur Glut eines greifbaren Du in diesem Zwischenbereich, zwischen Engel und Stein, wo „des

\footnotetext{
${ }^{35}$ Innerhalb des nun oft beschriebenen Kreislaufs von Liebesblick und Liebesqual, passt sich das Bild der schaumgeborenen Venus auch in das Assoziationsfeld der hyperbolischen Metapher des Tränen-Meers ein: auch das Tränenmeer des Liebenden kann die in ihm geborene Venus nicht löschen. So manieriert sich dieses seltsame Geschehen hier präsentiert, so spiegelt sich in diesem Kleinstmythos die gängige Vorstellung, wie es zur Liebe kommt. Es ist die allegorische Version der alten Idee, dass durch den zündenden Blick der Geliebten im Herz des Liebenden die Liebe entbrennt. Es so gedrängt paradox $\mathrm{zu}$ fassen, ist dann Hofmannswaldaus Kunst.

${ }^{36}$ Es ist dies eine gern und oft zitierte Erklärung für die Vorstellungsgabe, das Erinnerungsbild, die nicht zuletzt im Zusammenhang mit den Liebestraktaten überliefert ist. Vgl. Platon, Theaitetos, 191d; Aristoteles, Über die Seele, II, 12, 424a; Aristoteles, Über Gedächtnis und Erinnerung, I, 450a; Plutarch, Dialog der Liebe, in: Moralia, IX.
} 
blutes regung“, der ,appetitus ${ }^{637}$, den Menschen beherrscht, auch wenn von Gott gegeben. ${ }^{38}$

Ursache und Ursprung dieser Liebe bleibt aber der heisse Blick der Geliebten. Sie ist schuld und darf deshalb den Liebenden für seine Liebe nicht strafen, sondern müsste ihre Augen dafür belangen. Raffiniert concettistisch zugespitzt wird hier die Frau als Verführerin, als „ursprung dieser qual“ des appetitus dargestellt. Die Strafe - falls denn eine - kommt ihr zu.

Und dann, zum Schluss, wird die auf den ersten Blick doch so ganz petrarkistisch scharf aufgebaute Szenerie der blitzenden Geliebten und des brennenden Liebenden in der Idylle aufgelöst. Nachdem die Liebeslust himmlisch legitimiert, die Schuld am Ganzen aber der Geliebten zugewiesen ist, kommt nun die Aufforderung an die Schuldige, ihr Opfer doch zu lieben. Und zwar nicht blitzend und sengend, sondern temperiert. Die grausame Hitze, die dem Sterblichen unerträglich ist, mildert sich da plötzlich zum "warmen sonnenschein “ und der Liebeskranke gesundet im Kleeblattdasein - wobei die ironische Gebärde nicht zu überhören ist. Der anfänglichen Bitte, den brennenden Strahl zurückzuhalten, steht am Schluss die Bitte um ein wenig Wärme gegenüber.

Das ganze Gedicht mündet, in der Gefasstheit des warmen Bildchens, mitten in der frühbürgerlichen Gesellschaft, wo in wohltemperierter Wärme ein EhePaar sitzt. Ist der Blitz der erotisierte Blick der Geliebten, ist der warme Sonnenschein das betrachtende Auge der Gattin.

Wurden bei Weckherlin die Erotik und Sexualität des Auges im Geistigen und Geistlichen sublimiert, sind sie hier in der Idylle gebannt, im hellen Bildchen, einem Emblem der Ehe, wo die Hitze zur Wärme wird, die Qual zum genügsamen Dasein.

Schickt das Auge der Geliebten Blitze, schwimmt das Auge des Liebenden in Tränen. Darf das Auge der Geliebten, will man das Spiel nicht verderben, nicht zum Ort greifbarer Sinnlichkeit werden, ist das Auge des Liebenden, als Ort des Martyriums, selbst in sinnlich-greifbarer Lustbeschreibung noch geheiligt. Dabei liefert das Aufeinanderprallen der Elemente von Feuer und Wasser im liebenden Auge das Grundparadox, auf dem die meisten Bilder und Minidramen sich gründen. Dabei hat auch diese scheinbar rein concettistisch metaphorische Kombination von Hitze und Wasser einen medizinischen Hintergrund, indem die Tränen bald als verwirrtes Blut, bald als Hirnfeuchtigkeit, die von der Hitze oder dem Druck der Traurigkeit herausgedrängt wird, gesehen wurden. ${ }^{39}$

\footnotetext{
${ }^{37}$ Beecher und Ciavolella (Anm. 7), 125.

${ }^{38}$ Eine tradierte Vorstellung ist, dass die Hitze des Blickes nicht nur das Hirn austrocknet, sondern auch das Blut kochen lässt, bis es, sozusagen weiss destilliert, zum Samen wird. - Nicht von ungefähr waren zwei mögliche Therapien des Liebeskranken der Coitus oder der Aderlass.

${ }^{39}$ Beecher und Ciavolella (Anm. 7), 278.
} 
Im Auge des Liebenden werden also die dulces amarities lokalisiert und thematisiert. Nicht im distanziert betrachteten Auge der Geliebten, sondern im eigenen Körper, greifbar, nah. Grosser Artist darin ist Fleming. Sein Sonett Von sich selber weist schon im Titel die Blickrichtung:

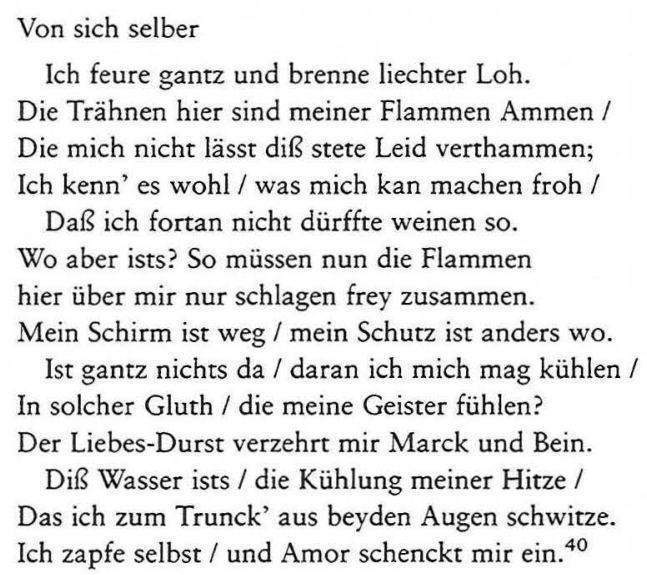

Hier ist die Geliebte nun vollends abwesend. Es braucht ihre Gegenwart nicht mehr, sondern im Gegenteil: nur dank ihrer Abwesenheit ist der beschriebene Zustand möglich. Ein Zustand, der als "stetes Leid“ dauerhaft ist, darin dem Leidenden auch die Qualität der Beständigkeit zuschreibt, eine Tugend. Es klingt hier das neostoizistische Harrungsvermögen des barocken Märtyrers an, die constantia des Gefolterten, der selbst in seinem Leid die Ursache der Marter nicht verdammt, seinen Gott nicht leugnet.

Auffallend ist, wie hier der Kreislauf, der sich sonst zwischen Liebendem und Geliebter einrichtet, im Liebenden allein sich schliesst. So ist das Brennen des Liebenden kurzgeschlossen mit seinen Tränen, die ihrerseits ja Folge dieses Brennens sind: Kind und Amme fallen zusammen. Ein Kurzschluss, der sich erklärt aus der Abwesenheit von "Schirm" und „Schutz". Dies nun aber ist ein Es, ein geschlechtsloses Rätsel-Es: „Wo aber ists?“

Der Liebeskranke, der sich verzehrt und austrocknet, ganz wie es im Buche steht, findet keine Kühlung für seinen Durst. Erst zum Schluss, als in der concettistischen Pointe der circulus vitiosus, der am Anfang als perpetuum mobile des Brandes gezeigt wird, durch eine leichte Verschiebung des Bildes zur Ersatz-Kühlung stilisiert wird, werden die Tränen zum Erfrischungsgetränk für den Austrocknenden. Dabei zapft er aber selbst. Reine Selbstbefriedigung auch wenn Amor als Schenke waltet, Amor, der als Feuerknabe die Flammen

\footnotetext{
${ }^{40}$ Paul Fleming, Deutsche Gedichte, hrsg. Volker Meid, Reclam Universal-Bibliothek 2455, Stuttgart 1986, 129.
} 
schürt, die eben die Tränen hervorbringen, usw. Es kommt zu einem Gelage mit sich selbst.

Diese Einsamkeit der Lust, wo gerade die Einsamkeit, die Verlassenheit, Bedingung der Lust ist, ist in gewisser Weise das Gegenstück zu dem Augengedicht von Weckherlin, wo das Objekt, das aus dem Körper der Geliebten ausgeschnittene Auge, zum Ausblick, zum Fenster zu Gott wird. Ist hier die Abwesenheit der Geliebten nur noch Auslöser eines selbständigen und selbstgefälligen Prozesses der Lust, nur noch wichtig als Abwesenheit eines Es, ist dort die Anwesenheit der Geliebten - auch wenn nur im Auge - allein wichtig als Auslöser einer diese übersteigenden, diese ausblendenden Erkenntnis und Betrachtung. Ist es dort die Erkenntnis Gottes, die durch das Auge der Geliebten gesucht wird, ist es bei Fleming die eigene Affektbewältigung und Stilisierung zum Märtyrer, die inszeniert wird. Bei beiden ist der Liebesblick, respektive die Liebe im Auge aber Ausdruck höchster Einsamkeit und Weltabgeschiedenheit. Die Geliebte hat hier keinen Platz, ist auch nicht verlangt, sondern soll nur stimulus sein für Reflexion und Selbstbetrachtung. Heilsegoismus, wenn man will.

Nur bei Hofmannswaldau ist die Geliebte in ihrer ganzen Körperlichkeit da, zumindest implizit, hat sie auch einen Namen. Und es kommt da so etwas wie ein erotisches Spiel zustande, auch wenn die eigentliche Lustbeschreibung die Geliebte ausschliesst. Denn so wie das Gedicht mit "Ich bin verletzt“ beginnt, geht es um die Qual und den Tod des Liebenden. Die Geliebte soll, blitzend und hitzend, lediglich Anlass bieten, soll Zündstein sein für Lust und Sexualtrieb des Liebenden. Sie soll aber auch - und das in strengem Gegensatz zu Fleming und dem eigentlich petrarkistischen Schema - sich schliesslich des Brennenden erbarmen. Wobei sich ein solches ,happy end' nur in der zur Wärme abgeschwächten Ehehitze anbietet.

In allen drei Beispielen wird aber die ganze Maschinerie der Liebespassion immer wieder und immer anders sublimiert, bis das im Körper wirkende erotische Spiel sich ganz zu einem intellektuellen Gespinst wandelt, wo die Lust im Witz steckt. Die passio des Körpers wird, in die Sprache übersetzt, zur passio des Wortes, die Lust der erotischen Begegnung wird zur Lust der besprochenen Einsamkeit.

Es ist nun interessant und im Parallelblick auch aufschlussreich zu sehen, was die persische Lyrik mit derselben Konstellation des passionierten Liebesblicks macht, wie er da verwandelt und verwörtlicht wird. Denn die Grundvorstellungen und darauf zurückgehenden Grundmetaphern sind ja dieselben.

Auch die persische Dichtung steht, wie gesagt, in dieser Tradition der Liebespassion, die sich von der Antike über den Neuplatonismus in die frühe Neuzeit zieht. Gleichzeitig ist die persische Dichtung aber durchtränkt von mystischem Gedankengut, so dass jeder einzelne Topos doppelgesichtig ist, janusköpfig, und oft nur in dieser Doppeltheit verstanden werden kann. Diese 
grosse mystische Tradition steht ihrerseits wieder in engem Zusammenhang mit der Rezeption des Neuplatonismus in Iran. Es schliesst sich hier ein Kreis, wie dies in ähnlicher Art vielleicht nur im Europa des 16./17.Jahrhunderts zu finden ist.

Anders als in der europäischen Dichtung des 17.Jahrhunderts, wo das Sonett - oder eine andere Gedichtform - sich zu einer thematischen Einheit schliesst, ist das persische Ghazal eine mehr oder weniger lose Reihung von in sich geschlossenen Einzelversen, die syntaktisch höchstens einmal sich über zwei Verse spannen, in der Regel aber den Einzelvers als Perle verstehen, die auf eine Kette gleichwertiger Perlen gereiht wird. Die Augenbeschreibungen und Augenbilder in der persischen Literatur finden sich so in einzelnen Versen, die Teil erotischer Gedichte sind. Diese nun aber sind nicht selten keine Liebesgedichte auf einen weltlich Geliebten, sondern stehen in jener mystischen Tradition, wo der ersehnte Geliebte, der quälende Geliebte, Gott ist, oder besser: auch Gott ist. Die meisten Liebesgedichte sind doppeldeutig, sind in ihrer Erotik sowohl weltlich als auch mystisch zu lesen.

Diese Ununterscheidbarkeit soll aber nicht weiter beirren, denn die Sprache ist bis ins Detail dieselbe. Und selbst im Geschlecht des Geliebten lässt sich kein Unterschied ausmachen, da in der klassischen persischen Lyrik die Liebe des Dichters sich auf einen männlichen Geliebten richtet. Ein Phänomen, das sich in seiner intellektuellen Ausformung wohl aus der platonischen, neuplatonischen Tradition erklären lässt.

Das Grundmuster kennen wir nun: Der Blick des Geliebten entzündet den Liebenden, macht dessen Auge weinen und verwirrt ihm den Sinn:

Der Glanz der Speerspitze steigt vom Herz in mein Auge, o Sâ'ib, wie denn sah dich diese verstopfte Quelle? ${ }^{41}$

Das persische Wort für Glanz ist dasselbe wie das für Wasser (âb), so dass der Glanz der Speerspitze auch Wasser des Speeres ist. Den Blick des Geliebten als Speer zu bezeichnen ist eingeschliffene Metapher, so dass im Kontext des ganzen Ghazals der Speer eindeutig als Liebesblick gelesen wird, der das Herz des Liebenden verletzt, um von da dann - als Wasser eben - wieder ins Auge des Liebenden zu steigen. Der klassische Kreislauf. Der Doppelsinn von Wasser und Glanz, der wieder als Metonymie für die Speerspitze gesetzt ist, ermöglicht nun aber die Pointe des zweiten Halbverses, wo rhetorisch gefragt wird, wie denn diese verstopfte Quelle, das weinende Auge, in der dieser Speer herumschwimmt, den Geliebten überhaupt sehen konnte. In für die persische Dichtung dieser Zeit typischer Manier wird hier mit Hilfe tropischer Aus-

${ }^{41}$ Sâ'ib-e Tabrîzî (1601-1676), Kulliyât, hrsg. A. Fîrûzkûhî, Tihrân (o.J.), Ghazal 4, Vers 7, 2. Die Übersetzungen bleiben - zum Teil auf Kosten der Eleganz - möglichst genau am persischen Text, um die Interpretation nachvollziehbar zu machen. 
drucksweise ein scheinbar einfaches Geschehen in die Absurdität getrieben. Mit dem Liebesblick an sich hat das nur noch in der vollkommen abstrakten Lust an der durch die Sprache ermöglichten Paradoxie etwas zu tun.

Mit demselben Doppelsinn von Wasser und Glanz spielend, setzt Kalîm die Pointe etwas anders:

Ganz von Kopf bis Fuss bist du Güte und Treue,

auf die Wunde der Jagdbeute streicht der Glanz deiner Speerspitze Salbe. ${ }^{42}$

Der Blick des Geliebten, der den Liebenden als Jagdbeute erlegt, ist gleichzeitig das Augenwasser, das dem Liebenden die Wunden salbt. Die Güte und Treue des Geliebten besteht so in der Grausamkeit, dass er ihn weinen macht. In der Realisierung der Metapher passiert hier nun aber eine Erotisierung des an sich nicht weniger abstrakten Vorgangs. Nicht nur assoziiert die Wunde der Jagdbeute Verfolgung und Geschlagenwerden, eine, wenn auch noch so schmerzhafte, Berührung, sondern diese Wunde wird dann auch noch vom Geliebten gesalbt. Die Lust am eigenen Leid, die Selbstsalbung sozusagen, wird durch die Metapher zur erotischen Berührung durch den Geliebten. Ist bei Sâ'ib die dem Blick eingeschriebene Distanz auch im Bild gewahrt, ist dieser Blick hier voll sinnlicher Nähe.

Das Auge des Geliebten schiesst aber nicht nur Pfeile, sondern sein brennender Blick legt auch Feuer ins Herz des Liebenden, ganz nach dem klassischen Schema:

Dein Zwinkern erledigte mein Herz mit einem Augenaufschlag, seit du den Mantelsaum bewegst, ist Feuer auf den Kebab gefallen. ${ }^{43}$

Das Lid des Auges, das im Augenaufschlag sich bewegt, ist der Mantelsaum, mit dem man das Feuer anfacht, auf dem das Fleisch geröstet wird. ,Den Mantelsaum bewegen' ist ein phraseologisch festgelegter Ausdruck für ,Feuer anfachen', eine Art erstarrte Metapher. Was für uns also vielleicht etwas sehr überladen daherkommt, ist im Persischen von einer unerhörten Eleganz, indem sich das ausgeführte Bild, die metaphora continuata, in die geläufige Sprache einbettet. Es ist nun aber nicht einfach der erstarrte Blick, der quält, der entzündet, der das Herz des Liebenden erledigt, sondern das Zwinkern und der Augenaufschlag. In diesem geliebten Auge gibt es Bewegung, gibt es ein erotisches Spiel. Und das ist ein entscheidender Unterschied zur deutschen Dichtung.

Auch wenn die grundsätzliche Spannung zwischen Liebendem und Geliebtem diese Leidensspannung bleibt - findet doch übers Auge ein Austausch statt; ein Schein-Austausch im wahrsten Sinn. So sagt Kalîm:

\footnotetext{
${ }^{42}$ Kalîm-e Kâshânî († 1651), Dîwân-e kâmil, hrsg. M. Afshâr, Tihrân 1362sh, Ghazal 168, Vers 7, 136.

${ }^{43}$ Kalîm-e Kâshânî (Anm. 42), Ghazal 79, Vers 3, 105.
} 
Wie oft dein magisches Auge das Herz von Kalîm stiehlt, jenes heimliche Kokettieren gibt das Herz uns wieder. ${ }^{44}$

Das Zauberauge, das magische Auge, ist das Auge, das den Liebenden verzaubert - eine Vorstellung, die eng zusammenhängt mit der Idee im Sehstrahl enthaltener spiritus. ${ }^{45}$ Eine Vorstellung, die auch in Europa geläufig war, in der Dichtung aber nicht diesen Stellenwert fand, wie in der persischen Dichtung. Der Diebstahl des Herzens andrerseits ist Topos. ${ }^{46}$

Auch hier wieder ist es nicht die unbewegte Ikone des Geliebten, die den Liebenden umtreibt, sondern der Geliebte ist der Akteur. Er stiehlt das Herz, und er gibt es durch das Kokettieren wieder. Dabei ist aber in diesen Kreislauf durch Blick und Augen-Koketterie - die Distanz eingeschrieben. Eine Distanz, die in seltsamem und seltsam spannendem Kontrast steht zur Heimlichkeit des Diebstahls und der Koketterie. Ein Kontrast, an dem sich die Szene heimlich erotisiert.

Es ist aber nicht nur der Liebende, der von den Augenblicken des Geliebten getroffen wird, sondern das eigene Auge ist mit denselben Eigenschaften wie das des Geliebten ausgestattet, nur ist die Wirkung nicht ganz zu vergleichen. Und das ist - mit wenigen Ausnahmen - ein grundlegender Unterschied zur europäischen Dichtung. So heisst es z.B.:

Jener trunkene Türke, wer ist es, auf dem Schiessplatz der Schönheit, der das Ziel mit den Pfeilen der Winke vergittert? ${ }^{47}$

Eines der häufigsten Epitheta für das Auge in der persischen Liebesdichtung ist ,trunken', ,betrunken'. Auch hier ist vielleicht aristotelische Tradition anzunehmen, wo Liebespassion und Trunkenheit verglichen werden. ${ }^{48}$ Tatsache ist, dass der trunkene Blick, das feuchte, schmachtende Auge, der Traum jedes persischen Liebenden ist. Dabei mag die Beliebtheit dieser Konnotation, die in der europäischen Lyrik keine Entsprechung hat, auch an der Pikanterie des Tabubruchs liegen, impliziert doch das trunkene Auge in der islamischen Kultur einen Gesetzesbruch.

Der Türke aber ist in der persischen Lyrik der schöne Geliebte schlechthin. Es ist der Türkensklave, der, als Sklave ideales Objekt der Begierde ist, als Geliebter ideales Bild des Tyrannen. Dabei gehört die Perversion der normalen hierarchischen Verhältnisse in der Liebe zur Lust, ist Teil des Spiels, das ja auch der europäische Petrarkismus kennt.

\footnotetext{
${ }^{44}$ Kalîm-e Kâshânî (Anm. 42), Ghazal 2, Vers 9, 79.

${ }^{45}$ Vgl. Anm. 18.

${ }^{46}$ Dabei kann im Persischen mit dem Ausdruck „das Herz geben“ gespielt werden, der auch: beherzen, ermutigen meint.

${ }^{47}$ Tâlib-e Amolî († 1626), Kulliyât, hrsg. T. Shihâb, [Tihrân] (o.J.), Ghazal 5, Vers 5 (5802), 221.

${ }^{48}$ Aristoteles, Nikomachische Ethik, B.VII, Kap.5, 1147a.
} 
Wenn hier nun vom trunknen Türken die Rede ist, meint dies das Auge des Geliebten, das schöne, schmachtende Auge. Dieses vergittert im Gesicht, dem Platz der Schönheit, da, wo das Ziel ist für die Geschosse der An-Schauenden, die Zielscheibe, nämlich das Auge, durch die eigenen Pfeile. Das ganze Geschehen spielt sich also auf dem Gesicht des Geliebten ab, auf dem, als einem Platz des Bogenschiessens, die Blicke der Schauenden das Ziel zu treffen suchen, das Auge, dieses aber von eignen Pfeilen verstellt vorfinden. Der Türke, der da als scheinbarer Spielverderber auftritt, ist also einerseits, im Rahmen des Platzes, das schöne Auge, anderseits aber wächst er auch assoziativ aus diesem Platz heraus und ist der Geliebte selber. Das ist eine Art der Bildkomposition, die am ehesten mit einem Kaleidoskop zu vergleichen ist. Ein ständiges Vergnügen, immer leicht anders, je nachdem, wie man es dreht. In diesem unerhört raffinierten Spiel des Verstandes, dieser abstrakten Komposition, verschwindet der Geliebte und mit ihm die in der neugierigen Anfangsfrage enthaltene erotische Spannung. Der Schiessplatz ist zu gross, das Ziel auch wenn vergittert - zu weit entfernt.

Die Idee des betrachteten Geliebten als Bühne, auf der sich ein Geschehen abspielt, findet sich häufig. So sagt Tâlib:

Aus Begierde geht das Auge einige Schritte mit dem Licht, im Rosengarten seiner Schönheit ist der Platz unseres Zuschauens. ${ }^{49}$

Das Bild beruht wieder auf der Idee, dass das Auge Licht aussendet. Licht, dem hier nun, in absurder Realisierung des Bildes, der Augapfel folgt, um Platz zu nehmen in den Zuschauerreihen des schönen Gesichts, das topisch als Rosengarten gesehen wird. Dabei kommt es implizit zu einer Berührung des Geliebten, da sich das Auge physisch in sein Gesicht setzt. Es ist eine fast schon surrealistisch anmutende Art der Vergrösserung, durch die die höchst subtile Angelegenheit des Liebesblicks plötzlich sozusagen fleischlich sichtbar wird, um in dieser Sichtbarkeit dann auch in der Erotik der Distanz, des Sehens, eine Erotik der Nähe, der Berührung, ahnen zu lassen. Und doch bleibt es schliesslich beim Zuschauen und beim Duft des Rosengartens.

Anders dann, wenn es zu direktem Blickkontakt kommt, wie im folgenden Vers von Tâlib:

Nachts öffnen wir die Tür zu jenem Mondgesicht, das Schloss der Wimpern öffnen wir mit den Fingerspitzen des Blicks. ${ }^{50}$

Der sonst verheimlichte Blick ins Auge des Geliebten wird in der Nacht, in der Heimlichkeit der Nacht, möglich. Dieser Nacht, in der das Mondgesicht fester Topos für das schöne Gesicht - aufgeht und scheint, der Nacht auch, wo der Diebstahl sich ereignet. Denn durch die Metaphern von Tür und Schloss

${ }^{49}$ Tâlib-e Amolî (Anm. 47), Ghazal 4, Vers 5 (5793), 220.

${ }^{50}$ Tâlib-e Amolî (Anm. 47), Ghazal 1171, Vers 1 (14419), 682. 
und Fingerspitzen assoziiert sich das Eindringen in einen verschlossenen Bereich - ohne Schlüssel, kurz: der Diebstahl. Indem nun aber dem Blick Fingerspitzen gegeben sind, die sich an den Wimpern des Geliebten mit wunderlicher Sorgfalt zu schaffen machen, vermischt sich der optische Sinn mit dem taktilen, sind dem Blick die Hände des Liebenden mitgegeben. Und so inszenieren sich in diesem nächtlichen Blick-Diebstahl ganz heimlich und ganz still Liebesnacht und körperliche Vereinigung.

Nicht immer ist die Begegnung aber so harmlos, meistens eigentlich nicht. Der Vierzeiler von Tâlib gibt da ein anderes Bild:

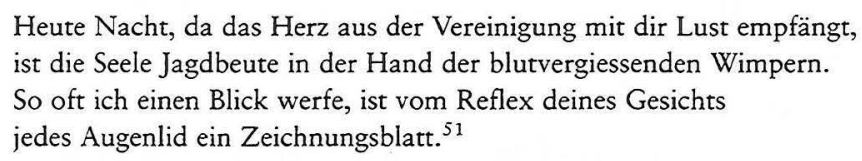

Die Jagdmetaphorik für die Liebe ist topisch. Der Reiz hier liegt aber in der Metapher der „Hand der blutvergiessenden Wimpern“, wo wieder im Blick die Berührung eingeschlossen ist. Dabei lässt sich die Metapher einerseits anthropomorphisierend lesen, wo dann die Wimpern zum Jäger werden, der seine Pfeile schiesst, anderseits aber assoziiert sich in der optischen Vorstellung in bezug auf die Wimpern sofort die Kralle, so dass die Metapher die Pranke eines Raubtiers meint, da dann auch eine Nähe inszeniert, die der Liebsvereinigung mehr entspricht als die Distanz des Pfeilschusses. Wundervoll ist nun aber die Weiterführung dieser Vereinigung, wo der Geliebte über den Blick ins Auge hereingeholt wird. Die Idee, dass das geschaute Bild des Geliebten sich in der Vorstellung des Liebenden einschreibt und da auch als Phantasiegebilde dann präsent sein kann, ist geläufig. Hier wird nun aber diese letzlich abstrakte Idee in das sichtbare Auge gefasst, indem das schauende Auge die Schönheit des Geliebten ins Innere des Augenlids reflektiert, so dass das Bild sich da - ins geschlossene Auge - einschreibt. Der Geliebte wird zur Miniatur auf dem Blatt des Augenlids. Gesehenes und Sehendes fallen zusammen. Eine Verwirklichung der Liebesvereinigung en miniature, wie sie sich nur ein spielerisch sich verlustierender, raffinierter Intellekt so lustvoll arrangieren kann.

Immer wieder ist die Vorstellung des ins Auge eingeschriebenen Bildes des Geliebten aufgenommen worden, vor allem in Zusammenhang mit den Traumbildern. Tâlib sagt:

\section{O du, der Ephebe deiner Traumgestalt ist bunte Augenstickerei, die fromme Stiftung des Heiligtums deiner Lieblichkeit ist der Gebetsteppich des Auges. ${ }^{52}$}

Auch hier das Bild des ins Auge gestickten Geliebten - ins Blasphemische überhöht, indem diese Augenstickerei als fromme Stiftung deklariert wird,

\footnotetext{
${ }^{51}$ Tâlib-e Amolî (Anm. 47), Rubâ'î 48, 904.

52 Tâlib-e Amolî (Anm. 47), Ghazal 1179, Vers 1 (14473), 685.
} 
Stiftung für das Heiligtum der Lieblichkeit des Geliebten, das heisst das Auge des Liebenden. Dies Auge, das aber auch, in absurder Bildkonzeption, auf dieser Augenstickerei, als dem Gebetsteppich seines eigenen Raumes, betet. Das Auge ist also sowohl der Raum des Betens als auch der Betende selber. In blasphemischer Allegorisierung wird die Lieblichkeit des Geliebten zum Heiligen, dessen Sanktuarium das Auge des Liebenden ist. Anders als bei Weckherlin, wo das Auge der Geliebten zwar zum Altar der Gottesanbetung, nie aber blasphemisch überhöht wird, wird hier gerade mit der Pikanterie dieser Grenzüberschreitung gespielt, indem die erotische Hingabe und Unterwerfung zur religiösen Hingabe und Unterwerfung stilisiert wird. - Und das ganze in der Augenhöhle.

Aber nicht nur das Auge des Liebenden wird zum Heiligtum stilisiert, sondern auch das Auge des Geliebten ist Heiligtum. So sagt Kalîm:

Den Indern ist kein Platz lieber als das Götzenhaus, das Mal hat entzückend Platz genommen im Winkel deines Auges. ${ }^{53}$

und bringt so eine phantastische Aitiologie für das Mal, den schwarzen Schönheitsfleck im Augenwinkel des Geliebten. Denn der Inder ist in der persischen Dichtung topisch mit schwarz konnotiert. Das Auge des Geliebten ist somit das Götzenhaus, der indische Tempel.

Oder Tâlib sagt:

Ich ziehe um, aus dem Kloster wende ich mich zur Moschee unter der Bedingung, dass dein Brauenbogen ihr Mihrab ist. ${ }^{54}$

Das Kloster ist der Ort, wo es Wein gibt, somit immer mit Trunkenheit, Weingenuss konnotiert. Hier nun will Tâlib die Trunkenheit durch Wein aufgeben für das Auge des Geliebten, mit dem seinerseits topisch auch die Trunkenheit assoziiert wird. Die Pointe des Verses besteht natürlich darin, dass die ,toubeh', die Umkehr des Dichters, seine Reue, vordergründig in die Moschee führt, darin aber sozusagen in die Traufe. Denn ist der Mihrab, das Allerheiligste dieser Moschee, der Brauenbogen des Geliebten, dient die ganze Metapher ausschliesslich zur hyperbolischen Beschreibung des Auges des Geliebten, dessen Trunkenheit die des Weines noch übertrifft. Es geht also nicht um eine Erhöhung des Geliebten in den Bereich des Sakralen - wie das in der barocken Dichtung zum Teil der Fall ist -, sondern mit Hilfe des Sakralen wird ein Bildbereich der Erotik erschlossen, der durch die leichte blasphemische Färbung an Pikanterie nur gewinnt.

Nicht nur bietet das Auge des Geliebten Trunkenheit, sondern das Auge des Liebenden findet im Geliebten, auf dem Geliebten, auf dieser Augen-Weide, Gaumenfreuden aller Art. Sâ'ib sagt:

\footnotetext{
53 Kalîm-e Kâshânî (Anm. 42), Ghazal 166, Vers 5, 135.

${ }^{54}$ Tâlib-e Amolî (Anm. 47), Ghazal 1060, Vers 5 (13622), 638.
} 
Unser Auge ist nicht wie die Asketen auf die Paradiesesfrucht aus, gierig nach einem Duft jener Kinnäpfel sind wir. ${ }^{55}$

Der Augenblick ist also erotisches Erlebnis im höchsten Grad. In ihm verlustieren sich alle anderen Sinne, ausser dem Gehör, für das mir kein einziger Beleg zugefallen ist - auch nicht in der europäischen Lyrik. Im AugenBlick ereignet sich feinsinnigstes und raffiniertestes Liebesspiel, im AugenRund dreht sich die ganze Welt nach den geistreichen Gesetzen der Erotik des Intellekts. Denn dass auch diese Szenerien sich nur in der Einsamkeit des von der Sprache besetzten und besessenen Auges aufbauen, ist klar. Auch hier geht es nicht um den realen Bezug zu einem Du, sondern um die Erotisierung der Phantasie und schliesslich unsere Lese-Lust.

Die Versklavung des Liebenden durch den Blick des Geliebten bleibt aber Grundvoraussetzung für dieses Spiel, das sich in dieser Spannung erst von Erniedrigung und Erhöhung, quälender Ablehnung und gnädiger Erlösung abwickelt. Erst in der passio, in der Krankheit, der Pathologisierung des Zustands, wird er für das einsame Ich, das darin seinen Intellekt anregt, interessant und erregend. Da, wo sich der Blick nicht mehr auf ein Du richtet und von dem aufgesogen wird, sondern, erotisch angeregt, entzündend wieder auf sich selbst zurückfällt.

Das Auge des Geliebten ist Fessel des Liebenden, in die dieser seine Existenz einschliesst und in deren Qual er sich definiert. Oder wie Sâ'ib sagt:

Es braucht keine Fangschnur für unsere Versklavung, eine Drehung des Auges genügt als Ring unserer Kette. ${ }^{56}$

So verschieden die Ver-dichtung dieses an sich gleichen Liebesblicks in Ost und West ist, vor allem was die Erotisierung betrifft, wo die deutsche Dichtung - und ich könnte auch sagen: die europäische Dichtung - sehr viel zurückhaltender ist, sind diese Liebesblicke doch da und dort letztlich Blicke der Einsamkeit, ist die Welt, die sich in ihnen erschafft, doch letztlich körperlos. Und diese Sprachlust kennt das Gespräch nicht, weder auf deutsch noch auf persisch.

\footnotetext{
${ }^{55}$ Sâ'ib-e Tabrîzî (Anm. 41), Ghazal 17, Vers 12, 8. Der Vergleich des Kinns mit dem Apfel ist Topos.

${ }^{56}$ Sâ'ib-e Tabrîzî (Anm. 41), Ghazal 13, Vers 1, 6.
} 